\title{
Insulin resistance and sympathetic function in high spinal cord injury
}

\author{
A-K Karlsson*,1 \\ ${ }^{1}$ Institute of Clinical Neuroscience, University of Göteborg, Sweden
}

\begin{abstract}
Objective: Cardiovascular disease (CVD) is today one of the main causes of death and affects spinal cord injured (SCI) earlier than able-bodied. Risk factors for CVD, such as decreased glucose tolerance, insulin resistance and increased fat mass, are all reported among SCI subjects and may be related to changes in sympathetic nervous system (SNS) function.

Methods: In order to test our hypothesis of a relationship between metabolic disturbances and alterations in SNS function, glucose and adipose tissue metabolism was investigated by the hyperinsulinaemic normoglycaemic clamp and microdialysis. Body composition was determined by DEXA-scanning. The SNS function was evaluated in total body as well as above and below lesion level by radiolabelled noradrenaline (NA) isotope dilution technique. A $24 \mathrm{~h}$ continuous plasma-NA monitoring was performed in seven SCI subjects.

Results: Following an oral glucose load the SCI group demonstrated normal glucose tolerance but impaired insulin sensitivity with a maximum insulin value of $83 \mathrm{mU} .1^{-1}$ in SCI compared to 50 in siblings, while adipose tissue metabolism was normal compared to siblings. Fat tissue mass constituted $34 \%$ of body mass in SCI group compared to $21 \%$ in weightmatched controls. Peripheral afferent activation resulted in increased blood pressure, decreased heart rate and reduction in muscle and skin blood flow. Furthermore, lipolysis below lesion level was activated by peripheral stimulation $\left(89-135 \mu\right.$ mol. $\left.1^{-1}\right)$. The $24 \mathrm{~h}$ continuous monitoring revealed p-NA levels $>1.40 \mathrm{nmol}^{-1}$ sufficient to induce lipolysis in $20 \%$ of the registrations. NA spillover below lesion level increased substantially following peripheral afferent stimulation $\left(0.06-0.90\right.$ pmol.min. $\left.{ }^{-1} .100 \mathrm{~g}^{-1}\right)$, whereas spillover above lesion level increased during central activation.

Conclusions: We found signs of decreased insulin sensitivity and increased fat tissue mass. Peripheral activation of SNS was visualised in the SCI group by increased transmitter spillover as well as increased lipolysis and vasoconstriction. The diurnal registration of NA levels indicated frequent episodes of peripheral sympathetic activation in the group. This may compensate for the inability of central activation of SNS and may contribute to maintain lipolysis activity as well as to generate insulin resistance in the group
\end{abstract}

Keywords: Spinal cord injury; metabolism; insulin resistance; automic dysreflexia; sympathetic nervous system; adipose tissue

\section{Introduction}

The expected survival following a spinal cord injury (SCI) is today approximately $80-85 \%$ of that in similarly aged able-bodied. ${ }^{1-3}$ An alteration in main causes of death has occurred, the genito-urinary diseases, accounting for half of the deaths in the late $1950 \mathrm{~s},{ }^{4}$ now cause a quarter $^{2}$ or less $^{3}$ of the total mortality, whereas cardiovascular (CVD) and respiratory diseases are now equally ${ }^{2,5}$ or more important as $^{2}$ primary death causes. We are facing a growing population of ageing spinal cord injured subjects, with a proposed increased prevalence ${ }^{7,8}$ and an earlier onset of CVD. ${ }^{2}$

Well-known risk factors for CVD such as obesity, impaired glucose tolerance, insulin resistance and

*Correspondence: A-K Karlsson, MD, PhD, Spinal Injury Unit, Sahlgrenska University Hospital, S-413 45 Göteborg, Sweden diabetes mellitus, ${ }^{9-11}$ exist in SCI subjects. Obesity is more prevalent in $\mathrm{SCI}^{12}$ than in able-bodied subjects and even among non-obese SCI subjects, a higher fat content than expected is found. ${ }^{13}$

Insulin resistance is strongly associated with CVD. ${ }^{9}$ In the insulin resistance condition the insulin effect in liver and muscle cells is deteriorated and the inhibitory effect on lipolysis is impaired. Increased insulin secretion may compensate for the reduced sensitivity to insulin action and blood glucose may thus be normal, but at the cost of increased insulin secretion.

When trying to explain the relationship between obesity/insulin resistance and cardiovascular morbidity among able-bodied some interest has been focused on sympathetic nervous system (SNS) activity. Associations between sympathetic activity and the degree of obesity, ${ }^{14}$ fat mass $^{15}$ weight gain ${ }^{15}$ carbohydrate 
intake $\mathrm{e}^{16,17}$ and plasma insulin levels ${ }^{18-20}$ are reported. Furthermore, a $\beta$-adrenergic stimulation per se induces an insulin resistance and a reduction of glucose uptake in the muscles. ${ }^{21}$

Spinal cord injury results in varying degrees of autonomic disturbances with effects also on metabolic regulation. Hypoglycaemia among subjects with high paraplegia and tetraplegia is accompanied by a reduction in blood pressure, absent increase of $p$ adrenaline $^{22}$ and noradrenaline ${ }^{23}$ and lack of neuroglycopenic symptoms. In tetraplegic patients, mental arousal, cold or pain stimuli above lesion level do not cause any significant cardiovascular response. ${ }^{24}$ However, somatosensory and visceral stimuli below lesion level produce an increase in blood pressure and decrease in muscle and skin perfusion below lesion level $^{24}$ and sometimes induce an exaggerated reaction, the autonomic dysreflexia (AD) reaction. ${ }^{25,26}$

In general, SCI subjects show a low sympathetic activity. Thus, plasma noradrenaline (NA) and adrenaline, ${ }^{27}$ the metabolites urinary 3-methoxy-4-hydroxyphenylethylglycol (MHPG), and vanillylmandelic acid (VMA), ${ }^{28}$ as well as intraneurally recorded muscle ${ }^{29}$ and skin $^{30}$ sympathetic nerve activity below lesion level, are reported to be low in SCI subjects during baseline conditions. During AD the plasma NA concentration increases $^{27}$ whereas microneurographic recordings, surprisingly, exhibit a very limited sympathetic activation. ${ }^{29,30}$ When evaluating sympathetic function by plasma NA determinations one must be aware that approximately $10 \%$ of the released transmitter reaches the circulation, ${ }^{31,32}$ the rest is subjected to neuronal and extraneuronal uptake, and also the blood-borne NA entering an organ is to a great extent being extracted. By the steady-state infusion of radiolabelled NA it is possible to evaluate the extraction and clearance of NA from plasma. Regional as well as organ NA spillover can be determined, thereby evaluating the differentiated sympathetic outlet.

In conclusion, the main risk factors for CVD prevalent in the SCI group are obesity, decreased glucose tolerance and insulin resistance, maybe associated with low HDL-cholesterol levels. These factors suggest the significance of the insulin resistance syndrome as a risk for CVD also in SCI subjects. A supposed lower sympathetic activity ${ }^{33}$ in the group would increase insulin sensitivity since mobilisation of FFA is increased during stress. The findings of insulin resistance in the group therefore seem contradictory and deserve further investigation. A proper evaluation of sympathetic function above and below lesion level seems appropriate.

\footnotetext{
Aims

Against the background: CVD morbidity and mortality increasingly important in SCI subjects; Insulin resistance and obesity being the major risk factors for CVD in SCI subjects; Insulin resistance reported to be related to SNS activity; Sympathetic activity supposed
}

to be low in SCI subjects; investigations of metabolism and sympathetic function in SCI subjects were performed. We addressed the following questions:

(1) Does the SCI group exhibit insulin resistance?

(2) Does the SCI group exhibit a low sympathetic activity?

(3) Does the peripheral activation of SNS play a role in metabolic regulation?

\section{Methods}

\section{Subjects}

SCI subjects with lesion level C6-T4 were investigated. The level of sympathetic disruption in SCI subjects was established by a forced perspiration test based on the characterisation of impaired sudomotor function in SCI subjects. ${ }^{34,35}$ Body composition was investigated by dual energy X-ray absorptiometry (DEXA)-scan. ${ }^{36}$ The DEXA-scan measurements characterised regional body composition in arm, leg, trunk and head. One control group consisted of siblings in order to adjust for heritage. Another control group consisted of weight-, age- and sex-matched unrelated subjects.

\section{Metabolism}

An oral glucose tolerance test (OGTT) was performed. Insulin sensitivity was investigated by the hyperinsulinaemic normoglycaemic clamp technique. ${ }^{37}$ Hyperinsulinaemia was generated by an insulin infusion of $1 \mathrm{mU} . \mathrm{kg}^{-1}$ body weight and glucose was infused to maintain normoglycaemia $\left(5 \mathrm{mmol} \cdot \mathrm{1}^{-1}\right)$. For details of methods see Karlsson et al. ${ }^{35}$

Subcutaneous adipose tissue metabolism was investigated by microdialysis, ${ }^{38}$ performed in adipose tissue above lesion level, in the clavicular region and below lesion level, in the umbilical region. A thin dialysis membrane was inserted into subcutaneous adipose tissue. The membrane was connected to a pump device, perfusing the system with a constant flow rate. The dialysates were collected in vials and changed every 10 or $15 \mathrm{~min}$. The system was calibrated individually in vivo. Lipolysis was studied during oral glucose tolerance test, centrally mediated sympathetic stimulations and induced autonomic dysreflexia. The microdialysis was combined with adipose tissue blood flow determinations by the ${ }^{133}$ Xenon-clearance methodology. ${ }^{39}$ For details of methods see Karlsson et al. ${ }^{35,40,41}$

Biopsies of subcutaneous fat cells were accomplished above and below lesion level for estimation of fat cell size ${ }^{42}$ and glucoregulatory hormones and plasma lipoproteins were measured.

\section{Sympathetic nervous system activity}

Sympathetic activity was assessed by the radiotracer dilution technique ${ }^{43}$ measuring total and regional NA 
spillover. NA spillover in the sympathetically decentralised legs was compared to the centrally innervated arm in SCI subjects and to able-bodied subjects, during basal condition, centrally mediated sympathetic stimulation (mental stress) and during peripheral afferent stimulation (bladder percussion). For details and equations see Karlsson et al. ${ }^{44}$ Blood flow was investigated by venous occlusion strain gauge plethysmography in arm and leg. Skin perfusion in toe and finger was investigated by laser doppler flowmetry.

In order to get a diurnal estimation of sympathetic activity in SCI subjects a continuous plasma noradrenaline monitoring during $24 \mathrm{~h}^{45}$ was performed. For details see Karlsson et al. ${ }^{41}$

\section{Results}

\section{Metabolism}

Glucose tolerance, insulin sensitivity and adipose tissue metabolism were evaluated in seven SCI subjects and their siblings. OGTT revealed a normal glucose tolerance but decreased insulin sensitivity in SCI subjects compared to siblings (see Figure 1). The hyperinsulinaemic normoglycaemic clamp, however, showed similar insulin sensitivity in the groups (see Table 1). Triglycerides, cholesterol, HDL-cholesterol as well as the counter-regulatory hormones growth hormone, glucagon and cortisol were similar in the groups (see Table 2). Adrenaline increased during the clamp in the sibling group.

Lipolytic rate was evaluated by microdialysis and the interstitial glycerol release was measured and found to be similar in the postabsorptive state in the groups. There was no difference between clavicular and umbilical regions within groups. Plasma insulin and glycerol was higher in the SCI group during postabsorptive state. Lipolysis was inhibited by the oral glucose load to the same degree in both groups and showed no regional differences.

During centrally mediated sympathetic stimulation glycerol production was unaltered in the SCI group, whereas it increased in the umbilical subcutaneous adipose tissue in controls. However, there were no significant differences between the groups in level of glycerol production in either region. P-glycerol, -FFA and -insulin increased in the control group but remained unaltered in the SCI group.

Bladder percussion was performed in eight SCI subjects in order to induce a dysreflexia reaction. The stimulation was successful in five subjects in whom mean arterial pressure MAP rose $(81 \pm 8$ to $114 \pm 11 \mathrm{mmHg}, P<0.05)$, heart rate fell $(70 \pm 3$ to $54 \pm 4$ beats.min $\left.{ }^{-1}, \quad P<0.05\right)$ and p-NA increased $\left(0.70 \pm 0.49\right.$ to $\left.3.27 \pm 1.56 \mathrm{nmol}^{-1}, P<0.05\right)$. Bladder percussion activated lipolysis in subcutaneous adipose tissue below lesion level but we found no reaction above lesion level. The stimulation of lipolysis was also demonstrated by an elevation of plasma glycerol. (see Table 3). Plasma insulin levels also

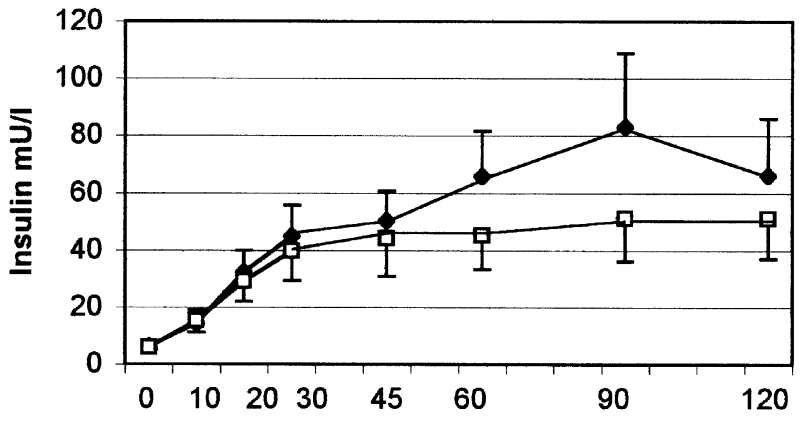

Figure 1 Oral glucose tolerance test. Insulin $\mathrm{mU} .1^{-1}$ in SCI group, filled symbols and siblings open symbols. Values are mean \pm SEM

Table 1 Insulin sensitivity

\begin{tabular}{lccc}
\hline & SCI subjects & Siblings & $\mathrm{P}$ \\
\hline $\begin{array}{c}\text { Gluclose infusion rate } \\
\text { mg.kg } \text { min }^{-1}\end{array}$ & $4.37 \pm 0.7$ & $5.20 \pm 0.6$ & n.s. \\
$\begin{array}{c}\text { Gluscose production } \\
\text { mg.kg } \text { min }^{-1}\end{array}$ & $0.47 \pm 0.47$ & $0.40 \pm 0.20$ & n.s. \\
$\begin{array}{c}\text { Glucose delivery } \\
\text { mg.kg }\end{array}$ & $5.13 \pm 0.71$ & $5.78 \pm 0.34$ & n.s. \\
\hline
\end{tabular}

Values are mean $\pm \mathrm{SEM}$; n.s., not significant

Table 2 Biochemical profile

\begin{tabular}{|c|c|c|}
\hline & $S C I$ & Controls \\
\hline B-glucose mmol.1 ${ }^{-1}$ & $4.61 \pm 0.1$ & $4.4 \pm 0.1$ \\
\hline Insulin $\mathrm{mU} .1^{-1}$ & $12.4 \pm 0.3$ & $16.9 \pm 0.4$ \\
\hline Triglycerides mmol. $1^{-1}$ & $1.20 \pm 0.32$ & $1.04 \pm 0.37$ \\
\hline Cholesterol mmol.1 ${ }^{-1}$ & $1.13 \pm 0.13$ & $1.19 \pm 0.16$ \\
\hline HDL mmol.1 $1^{-1}$ & $1.25 \pm 0.11$ & $1.19 \pm 0.16$ \\
\hline FFA mmol.1 ${ }^{-1}$ & $0.75 \pm 0.08$ & $0.75 \pm 0.05$ \\
\hline Growth hormone nmol.1 ${ }^{-1}$ & $4.14 \pm 1.33$ & $\begin{array}{c}1.01 \pm 0.46 \\
P<0.05\end{array}$ \\
\hline Adrenaline nmol.1 ${ }^{-1}$ & $0.01 \pm 0.01$ & $0.13 \pm 0.07$ \\
\hline Noradrenaline nmol.1 ${ }^{-1}$ & $0.99 \pm 0.29$ & $1.53 \pm 0.36$ \\
\hline Glucagon pmol.1 $1^{-1}$ & $17.44 \pm 1.43$ & $16.54 \pm 0.85$ \\
\hline C-peptide nmol. $1^{-1}$ & $0.60 \pm 0.12$ & $0.53 \pm 0.05$ \\
\hline Cortisol nmol.1 ${ }^{-1}$ & $340.7 \pm 26.7$ & $367.3 \pm 47.5$ \\
\hline
\end{tabular}

increased following bladder percussion $(8.6 \pm 1.3 v s$ $\left.10.4 \pm 1.3 \mathrm{mU} .1^{-1}, P<0.05\right)$.

The 24-h continuous plasma NA-monitoring in seven SCI subjects revealed a mean venous plasma NA concentration of $1.04 \pm 0.03 \mathrm{nmol}^{-1}$. Furthermore, $20 \%$ of the 30 -min samples showed NA levels $>1.40$ nmol. $1^{-1}$ (the plasma NA level where a control group activated lipolysis by central sympathetic activation, mental stress ${ }^{41}$ ).

The groups were weight matched but body composition diverged substantially. Lean body mass constituted only $60 \%$ of total weight in SCI subjects compared to $75 \%$ in controls. Total fat content was 
$33.8 \pm 2.6 \%$ compared to $20.1 \pm 1.6 \%$, respectively $(P<0.01)$. See Table 4 for body composition. A fat cell biopsy above and below lesion level showed similar fat cell size in the groups.

\section{Sympathetic function}

Regional and total body NA spillover and NA clearance were evaluated in nine SCI subjects and ten control subjects, during basal conditions, centrally mediated stimulation and in SCI subjects also during peripheral afferent stimulation.

MAP and heart rate were similar in SCI and control subjects during baseline. Total body and regional NA spillover, arterial NA concentrations and total body and leg NA clearance showed no significant differences between the groups during resting, supine conditions (see Table 5).

Centrally mediated SNS activation increased MAP and heart rate in both groups. Heart rate was higher in the SCI group than in controls during mental stress. Vascular resistance decreased in arm but was unaltered in leg among SCI subjects. Control subjects decreased leg vascular resistance.

Total body NA spillover only showed a tendency to increase in SCI subjects, whereas it increased significantly in control subjects. Arm NA spillover increased in SCI group and was higher than in control subjects. Leg NA spillover increased in control subjects (see Table 5).

Bladder percussion in SCI subjects increased MAP and leg vascular resistance and toe skin perfusion decreased by $56 \%$. Leg NA spillover increased 15 -fold during bladder stimulation and total body NA spillover showed a tendency to increase (see Table 5).

Table 3 Lipolysis during autonomic dysreflexia. Glycerol $\mu \mathrm{mol}^{-1} 1^{-1}$

\begin{tabular}{lccc}
\hline & Rest & $\begin{array}{l}\text { Autonomic } \\
\text { dysreflexia }\end{array}$ & $\mathrm{P}$ \\
\hline $\begin{array}{l}\text { Interstitial glycerol } \\
\text { above lesion level }\end{array}$ & $113 \pm 10$ & $126 \pm 42$ & n.s. \\
$\begin{array}{c}\text { Interstitial glycerol } \\
\text { below lesion level }\end{array}$ & $89 \pm 12$ & $135 \pm 21$ & $<0.05$ \\
Plasma glycerol & $91 \pm 8$ & $123 \pm 16$ & $<0.05$ \\
\hline
\end{tabular}

Values are mean \pm SEM; n.s., not significant

\section{Discussion}

The SCI subjects displayed metabolic and body composition alterations, such as insulin resistance and an enlarged proportion of body fat, similar to those found in obese individuals in spite of a normal body weight in SCI subjects. Stimulation below lesion level activated lipolysis. This may play a compensatory role for the loss of central activation but a pathophysiological role may also be suspected by contributing to insulin resistance. Furthermore, the decentralised sympathetic nerves were readily activated during peripheral stimulation as revealed by a marked increase in NA spillover below lesion level. Sympathetic activity was similar to able-bodied during resting, supine conditions, but was more readily activated above lesion level during central activation.

\section{Metabolism}

We found no differences between the groups in lipolytic rate in spite of an inability to activate lipolysis by centrally mediated SNS stimulations in SCI subjects. The activation of lipolysis during peripheral afferent stimulation, together with the signs of rather frequent episodes of stimulations may play a compensatory role for the inability to activate lipolysis by a central command. Furthermore it may be of importance during physical exercise and athletics. Induction of an autonomic dysreflexia reaction, so called 'boosting', is commonly used by SCI athletes ${ }^{46}$ and improved results especially during long-distance

Table 4 Body composition

\begin{tabular}{llcc}
\hline & SCI & Controls & $\mathrm{P}$ \\
\hline$n$ & 10 & 10 & \\
Age & 39 & 33 & n.s. \\
Weight $(\mathrm{kg})$ & 77.1 & 79.4 & n.s. \\
LBM (kg) & 47.7 & 60.2 & $<0.01$ \\
\% lean total body & 66 & 76 & $<0.01$ \\
\% fat tissue & & & \\
$\quad$ total & 32 & 21 & $<0.01$ \\
$\quad$ arms & 26 & 20 & $<0.01$ \\
$\quad$ legs & 33 & 20 & $<0.01$ \\
$\quad$ trunk & 32 & 21 & $<0.01$ \\
\hline
\end{tabular}

Table 5 Sympathetic function

\begin{tabular}{|c|c|c|c|c|c|c|}
\hline & $\begin{array}{l}\text { Resting } \\
\text { SCI }\end{array}$ & Control & $\begin{array}{l}\text { Mental stress } \\
\text { SCI }\end{array}$ & Control & $\begin{array}{l}\text { Resting } \\
\text { SCI }\end{array}$ & $\begin{array}{c}\text { Bladder } \\
\text { percussion } \\
\text { SCI }\end{array}$ \\
\hline Total body NA spillover pmol.min ${ }^{-1}$ & 2163 & 2826 & 2646 & $3783^{\mathrm{a}, \mathrm{b}}$ & 2526 & 3999 \\
\hline Arm NA spillover pmol.min $100 \mathrm{~g}^{-1}$ & 1.56 & 1.58 & $2.73^{\mathrm{a}, \mathrm{b}}$ & 1.71 & 1.92 & 1.78 \\
\hline Leg NA spillover pmol.min $100 \mathrm{~g}^{-1}$ & 0.22 & 0.23 & -0.16 & $0.41^{\mathrm{a}, \mathrm{b}}$ & 0.06 & $0.90^{\mathrm{b}}$ \\
\hline Arterial NA nmol.1 ${ }^{-1}$ & 1.29 & 1.26 & 1.37 & 1.46 & 1.37 & $2.55^{\mathrm{b}}$ \\
\hline Leg NA clearance ml.min ${ }^{-1} 100 \mathrm{~g}^{-1}$ & 0.36 & 0.37 & & & & \\
\hline
\end{tabular}

${ }^{a}$ Significant difference between groups, $\mathrm{P}<0.05$; ${ }^{\mathrm{b}}$ significant difference between rest-stimuli within groups, $P<0.05$ 
races are reported. 'Boosting' is accompanied by increased NA levels. ${ }^{47}$ Our investigations suggest an increased supply of substrates for metabolism during 'boosted' conditions.

The atrophy of lean body mass in denervated regions was partly replaced by an increase in adipose tissue mass. It is known that visceral adipose tissue accumulation is more strongly associated with increased CVD risk. ${ }^{48}$ The exact location of adipose tissue accumulation is not determinable by the DEXAscanning method since this technique does not separate subcutaneous adipose tissue from visceral or inter- or intra-muscular depots. Atrophic muscles seem to be replaced by fat also in other neuromuscular disturbances. $^{49}$ Animal studies suggest a role of sympathetic denervation in adipose tissue growth. ${ }^{50}$ However, in SCI subjects, fat depots are not denervated only decentralised; therefore the above finding ${ }^{50}$ is presumably not totally applicable. Furthermore, the unchanged fat cell size and lack of difference in lipolytic activity in decentralised regions argue against a decreased sympathetic activity as the main cause of adipose tissue accumulation.

The oral glucose tolerance test revealed a normal glucose tolerance, but the SCI subjects needed a higher p-insulin to maintain normoglycaemia; ie they were insulin resistant. However, unexpectedly this was not demonstrated during the normoglycaemic, hyperinsulinaemic clamp. The activation of the adrenal medulla in the sibling group may be part of the explanation, since adrenaline is known to decrease insulin sensitivity, ${ }^{51}$ that is both groups exhibited insulin resistance. Furthermore, others have reported decreased insulin sensitivity in tetraplegic subjects during insulin clamp. ${ }^{52}$

It may be speculated that the frequent activation of lipolysis during peripheral afferent stimulations, may contribute to the generation of insulin resistance among SCI subjects. Furthermore the alterations in body composition following SCI may make the group more susceptible to the negative effects of FFA release. The combination of a higher fat content and reduced skeletal muscle mass may result in even more pronounced competition between FFA and glucose oxidation. The alterations in body composition following a spinal cord injury also affect muscle morphology, and resembles alterations in obese subjects. ${ }^{53}$ Muscle fibre area is decreased by $40 \%$, type I fibres are very rare in paralysed regions and there is an alteration from insulin sensitive Type IIA fibres to less insulin sensitive type IIB fibres. ${ }^{52}$ The insulin mediated glucose uptake in denervated muscles in SCI subjects has been investigated in vitro, and was, however, found to be normal. ${ }^{52}$ A clear relationship between the reduction in lean body mass and amplitude of impaired insulin sensitivity has been demonstrated. $^{52}$

Some data in the present studies indicate that changes occur with respect to age and duration of injury. We found a positive correlation between age and p-insulin levels in both groups, whereas there was a negative correlation between duration of injury and basal venous p-NA in SCI subjects. This may indicate an ongoing peripheral denervation. Whether this also implies a decreased frequency of peripheral activation of SNS is not known.

\section{Sympathetic function}

Sympathetic nerves below lesion level were readily activated during bladder stimulation. Vasoconstriction was induced in leg muscle and skin and NA spillover increased markedly. The increase in leg NA spillover during bladder percussion was in the same magnitude as the increase during mental stress in control subjects (see Figure 2). Several factors such as increased blood flow, ${ }^{54}$ nerve firing rate or nerve density ${ }^{55}$ are known to increase NA spillover. None of these seem to have contributed to the NA spillover rise in decentralised leg, since blood flow actually decreased, and nerve firing rate is reported to be low even during bladder stimulation. $^{29,30}$

The marked increase in leg NA spillover appears contradictory to the findings during microneurographic registrations, where skin and muscle sympathetic nerves showed a very sparse activity below lesion level both at baseline and during bladder stimulation. $^{29,30}$ Receptor supersensitivity has been discussed and also indicated in tetraplegics receiving NA-infusion. ${ }^{56}$ However, the exaggerated blood pressure response in the latter study was interpreted to be due to inability of baroreceptor modulation. Skin sympathetic nerve endings ${ }^{57}$ and platelet alfaadrenoceptor number are normal in tetraplegic subjects. ${ }^{58}$ These facts, together with our finding of a 15-fold increase in leg NA spillover, may indicate that receptor supersensitivity is not inevitably needed to explain the dysreflexia reaction. Maybe an altered amount of transmitter release per nerve impulse might

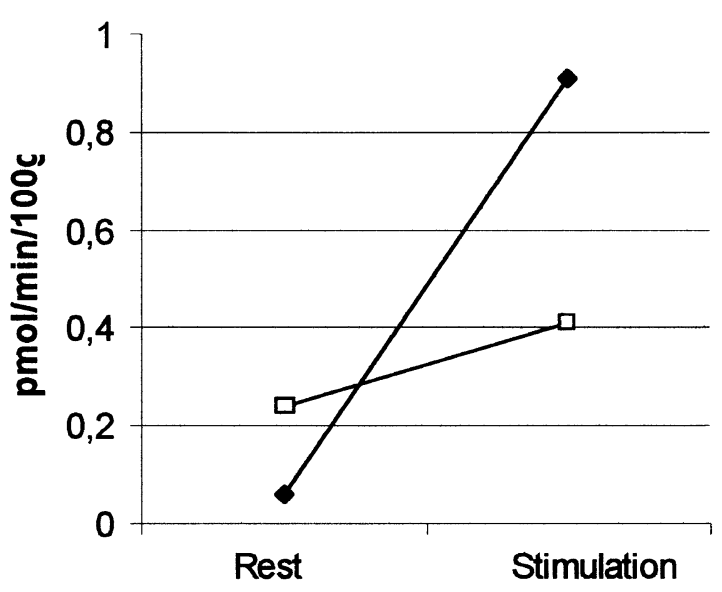

Figure 2 Leg NA spillover during rest and bladder percussion in SCI subjects (filled symbols) and during rest and mental stress in control subjects (open symbols) 
explain the discrepancy between microneurographic and leg NA kinetic determinations. Furthermore, animal experiment have shown a clear increase in renal sympathetic nerve activity during autonomic dysreflexia. $^{59}$

The autonomic dysreflexia reaction is presumably mediated via a spinal reflex arc. Whether this reflex arc is created or just exaggerated by spinal cord lesion is not known. Animal studies have revealed alterations in preganglionic sympathetic nerves in the medulla. Experimental spinal cord injury is associated with degeneration of sympathetic nerves, followed by signs of sprouting and new synapse formation above as well as below lesion level. ${ }^{59-61}$ This remodelling of SNS in the spinal cord may contribute by adding new synapses that spreads the reaction.

Total body and regional NA spillover were the same in SCI subjects and controls at baseline, in spite of decentralisation. One possible explanation for this unexpected finding may be the increase in NA spillover demonstrated during peripheral afferent stimulation, and the signs of rather frequent episodes seen during the $24 \mathrm{~h}$ continuous NA monitoring. The relatively sparse contribution from lower parts of the body to total body NA spillover, visualised among able-bodied, ${ }^{44}$ may constitute another part of the explanation. However, the lack of difference in total body NA spillover is divergent to a previous finding by Krum et $a l^{62}$ who showed a lower total body NA spillover in SCI subjects. There were differences in lesion levels that may imply intact SNS innervation of the heart and the lungs in the present group in contrast to the group investigated by Krum et al. ${ }^{62}$ NA spillover from heart and lungs constitutes about $6 \%{ }^{63}$ and $30 \%{ }^{64}$ respectively of total body NA spillover in able-bodied. Centrally mediated SNS stimulation resulted in an elevated MAP in SCI subjects, mainly through an increase in heart rate in contrast to previous findings ${ }^{24}$. The discrepancy may be explained by an intact heart innervation in the present group contrary to the study group investigated by Corbett. $^{24}$ The finding of a greater increase in heart rate and in arm NA spillover in SCI subjects than in control is interesting and indicate altered sympathetic function also above lesion level.

The basis of the present investigations was the notion of SCI subjects exhibiting insulin resistance in combination with a low sympathetic activity. Our studies confirmed the insulin resistant state in the SCI subjects but they did not present a low sympathetic activity. SNS was not activated by centrally mediated stimulations and this may be of importance in glucose counter-regulation, during stress and physical activity. However, peripheral afferent stimulation showed that the decentralised sympathetic nerves are intact and possible to activate. Metabolically this may serve as a compensatory mechanism during for instance exercise. A pathophysiological role may be suspected since repeat episodes of activation of lipolysis may contribute to the insulin resistance.
The marked NA spillover above lesion level during mental stress and below lesion level during autonomic dysreflexia indicate an altered sympathetic function above as well as below lesion level following spinal cord injury.

The present findings also have clinical implications. Attention must be paid to the fact that even lean SCI subjects may exhibit metabolic alterations that necessitates investigation and treatment. Furthermore, the tendency to induce metabolic alterations associated with cardiovascular risk factors adds a further indication for treatment of underlying causes of autonomic dysreflexia. The present data also emphasise the importance of a proper and active rehabilitation of the group as a mean of reducing risk factors for the main cause of death, cardiovascular disease.

\section{References}

1 Geisler WO et al. Survival in traumatic spinal cord injury. Paraplegia 1983; 21: $364-373$

2 Whiteneck GG et al. Mortality, morbidity, and psychosocial outcomes of persons spinal cord injured more than 20 years ago. Paraplegia 1992; 30: 617-630.

3 Hartkopp A et al. Survival and causes of death after traumatical spinal cord injury. A long term epidemiological survey from Denmark. Spinal Cord 1997; 35: 76-85.

4 Breithaupt D, Jousse A, Wynne-Jones M. Late causes of death and life expectancy in paraplegia. CMAJ 1961; 85: 73-77.

5 Krause JS, Kjorsvig JM. Mortality after spinal cord injury: a four-year prospective study [published erratum appears in Arch Phys Med Rehabil 1992; 73(8): 716]. Arch Phys Med Rehabil 1992; 73: $558-563$

6 DeVivo MJ, Black KJ, Stover SL. Causes of death during the first 12 years after spinal cord injury. Arch Phys Med Rehabil 1993; 74: $248-254$.

7 Yekutiel $\mathrm{M}$ et al. The prevalence of hypertension, ischaemic heart disease and diabetes in traumatic spinal cord injured patients and amputees. Paraplegia 1989; 27: 58 -62.

8 Bauman WA et al. Coronary artery disease: metabolic risk factors and latent disease in individuals with paraplegia. Mt Sinai J Med 1992; 59: $163-168$.

9 Reaven GM. Banting lecture 1988. Role of insulin resistance in human disease. Diabetes 1988; 37: 1595-1607.

10 Duckworth WC et al. Glucose intolerance due to insulin resistance in patients with spinal cord injuries. Diabetes 1980; 29: $906-910$

11 Bauman WA, Spungen AM. Disorders of carbohydrate and lipid metabolism in veterans with paraplegia or quadriplegia: a model of premature aging. Metabolism 1994; 43: 749 - 756 .

12 Levi R, Hultling C, Seiger A. The Stockholm Spinal Cord Injury Study. 3. Health-related issues of the Swedish annual level-ofliving survey in SCI subjects and controls. Paraplegia 1995; 33: $726-730$.

13 Spungen AM et al. Measurement of body fat in individuals with tetraplegia: a comparison of eight clinical methods. Paraplegia 1995; 33: $402-408$.

14 Scherrer U et al. Body fat and sympathetic nerve activity in healthy subjects. Circulation 1994; 89: $2634-2640$.

15 Spraul $\mathrm{M}$ et al. Reduced sympathetic nervous activity. A potential mechanism predisposing to body weight gain. $J$ Clin Invest 1993; 92: $1730-1735$.

16 Berne C, Fagius J, Niklasson F. Sympathetic response to oral carbohydrate administration. Evidence from microelectrode nerve recordings. J Clin Invest 1989; 84: $1403-1409$.

17 Heseltine $\mathrm{D}$ et al. Blood pressure, heart rate and neuroendocrine responses to a high carbohydrate and a high fat meal in healthy young subjects. Clin Sci Colch 1990; 79: 517-522. 
18 Rowe JW et al. Effect of insulin and glucose infusions on sympathetic nervous system activity in normal man. Diabetes 1981; 30: $219-225$.

19 Anderson EA et al. Hyperinsulinemia produces both sympathetic neural activation and vasodilation in normal humans. $J$ Clin Invest 1991; 87: $2246-2252$.

20 Berne $\mathrm{C}$ et al. The sympathetic response to euglycaemic hyperinsulinaemia. Evidence from microelectrode nerve recordings in healthy subjects. Diabetologia 1992; 35: $873-897$.

21 Lager I et al. Studies on the insulin-antagonistic effect of catecholamines in normal man. Evidence for the importance of beta 2-receptors. Diabetologia 1986; 29: 409-416.

22 Mathias CJ et al. Physiological responses to insulin hypoglycaemia in spinal man. Paraplegia 1979; 17: 319-326.

23 Palmer JP et al. Glucagon response to hypoglycemia in sympathectomized man. J Clin Invest 1976; 57: 522-525.

24 Corbett JL, Frankel HL, Harris PJ. Cardiovascular reflex responses to cutaneous and visceral stimuli in spinal man. $J$ Physiol Lond 1971; 215: 395-409.

25 Guttman L, Whitteridge D. Effects on bladder distension on autonomic mechanisms after spinal cord injuries. Brain 1949; 70: $361-405$.

26 Kewalramani LS. Autonomic dysreflexia in traumatic myelopathy. Am J Phys Med 1980; 59: 1-21.

27 Mathias CJ et al. Plasma catecholamines during paroxysma neurogenic hypertension in quadriplegic man. Circ Res 1976; 39: $204-208$.

28 Harvey RF et al. Catecholamine metabolites in spinal cord injury. Arch Phys Med Rehabil 1982; 63: 419-422.

29 Stjernberg L, Blumberg H, Wallin BG. Sympathetic activity in man after spinal cord injury. Outflow to muscle below the lesion. Brain 1986; 109: 695-715.

30 Wallin BG, Stjernberg L. Sympathetic activity in man after spinal cord injury. Outflow to skin below the lesion. Brain 1984; 107: $183-198$.

31 Esler M. Overflow of catecholamine neurotransmitters to the circulation: source, fate, and functions. Physiol Rev 1990; 70: $963-985$.

32 Eisenhofer G et al. Neuronal uptake, metabolism, and release of tritium-labeled norepinephrine during assessment of its plasma kientics. Am J Physiol 1991; 261: E505-E515.

33 Mathias CJ, Frankel HL, Bannister R, Mathias CJ, (eds). Autonomic disturbances in spinal cord lesions. In: Autonomic failure. 2nd edn. Oxford University Press. 1992; 839-881.

34 Normell LA. Distribution of impaired cutaneous vasomotor and sudomotor function in paraplegic man. Scand J Clin Lab Invest 1974; 138: $25-41$.

35 Karlsson AK et al. Influence of the sympathetic nervous system on insulin sensitivity and adipose tissue metabolism: a study in spinal cord-injured subjects. Metabolism 1995; 44: 52-58.

36 Mazess RB, Peppler WW, Gibbons M. Total body composition by dual-photon (153Gd) absorptiometry. Am J Clin Nutr 1984 40: $834-839$

37 DeFronzo RA, Tobin JD, Andres R. Glucose clamp technique: a method for quantifying insulin secretion and resistance. $A m J$ Physiol 1979; 237: E214-E223.

38 Lonnroth P, Jansson PA, Smith U. A microdialysis method allowing characterization of intercellular water space in humans. Am J Physiol 1987; 253: E228-E231.

39 Larsen OA, Lassen NA, Quaade F. Blood flow through human adipose tissue determined with radioactive xenon. Acta Physiol Scand 1996; 66: $337-345$

40 Karlsson AK et al. Regulation of lipolysis by sympathetic nervous system. A microdialysis study in normal and spinal cord injured subjects. Metabolism 1997; 46: 388 - 394.

41 Karlsson AK et al. Peripheral afferent stimulation of decentralised sympathetic neurones activates lipolysis in spinal cord injured subjects. Metabolism 1997; 46: 1465-1469.

42 Jacobsson B, Smith U. Effect of cell size on lipolysis and antilipolytic action of insulin in human fat cells. J Lipid Res 1972 13: $651-656$
43 Esler M et al. Determination of norepinephrine apparent release rate and clearance in humans. Life Sci 1979; 25: 1461 - 1470.

44 Karlsson AK et al. Differentiated norpinephrine spillover in human skeletal muscle. Am J Physiol 1997; 273: R16-R21.

45 Kowarski A et al. Determination of integrated plasma concentrations and true secretion rates of human growth hormone. J Clin Endocrinol Metab 1971; 32: 356-360.

46 Burnham R et al. Intentional induction of autonomic dysreflexia among quadriplegic athletes for performance enhancement; efficiacy, safety and mechanisms of action. Clin J Sport Med 1994; 4: $1-10$.

47 Wheeler $\mathrm{G}$ et al. Testosterone, cortisol and catecholamine responses to exercise stress and autonomic dysreflexia in elite quadriplegic athletes [see comments]. Paraplegia 1994; 32: 292 299.

48 Larsson $\mathrm{B}$ et al. Abdominal adipose tissue distribution, obesity, and risk of cardiovascular disease and death: 13 year follow up of participants in the study of men born in 1913. Br Med J Clin Res Ed 1984; 288: 1401 - 1404.

49 Grimby G, Kvist H, Grangard U. Reduction in thigh muscle cross-sectional area and strength in a 4-year follow-up in late polio. Arch Phys Med Rehabil 1996; 77: 1044- 1048.

50 Cousin B et al. Local sympathetic denervation of white adipose tissue in rats induces preadipocyte proliferation without noticeable changes in metabolism. Endocrinology 1993; 133: $2255-$ 2262 .

51 Attvall S et al. Early posthypoglycemic insulin resistance in man is mainly an effect of beta-adrenergic stimulation. J Clin Invest 1987; 80: 437 - 442

52 Aksnes AK et al. Intact glucose transport in morphologically altered denervated skeletal muscle from quadriplegic patients. Am J Physiol 1996; 271: E593-E600.

53 Krotkiewski M, Bjorntorp P. Muscle tissue in obesity with different distribution of adipose tissue. Effects of physical training. Int $J$ Obes 1986; 10: $331-341$.

54 Chang PC, van der Krogt JA, van Brummelen P. Demonstration of neuronal and extraneural uptake of circulating norepinephrine in the forearm. Hypertension 1987; 9: 647-653.

55 Yamaguchi N, de Champlain J, Nadeau RA. Regulation of norepinephrine release from cardiac sympathetic fibers in the dog by presynaptic alpha- and beta-receptors. Circ Res 1977; 41: $108-117$.

56 Mathias CJ et al. Enhanced pressor response to noradrenaline in patients with cervical spinal cord transection. Brain 1976; 99: $757-770$.

57 Norberg KA, Normell LA. Histochemical demonstration of sympathetic adrenergic denervation in human skin. Acta Neurol Scand 1974; 50: $261-271$.

58 Davies IB et al. Agonist regulation of alpha-adrenergic receptor responses in man. J Cardiovasc Pharmacol 1982; 4: S139-S144.

59 Maiorov DN, Weaver LC, Krassioukov AV. Relationship between sympathetic activity and arterial pressure in conscious spinal rats. Am J Physiol 1997; 272: H625-H631.

60 Krassioukov AV, Weaver LC. Morphological changes in sympathetic preganglionic neurons after spinal cord injury in rats. Neuroscience 1996; 70: $211-225$.

61 Krassioukov AV, Weaver LC. Reflex and morphological changes in spinal preganglionic neurons after cord injury in rats. Clin Exp Hypertens 1995; 17: $361-373$.

62 Krum $\mathrm{H}$ et al. Steady stae plasma [3H]-noradrenaline kinetics in quadriplegic chronic spinal cord injury patients. $J$ Auton Pharmacol 1990; 10: 221 - 226

63 Eisenhofer G et al. Regional release and removal of catecholamines and extraneuronal metabolism to metanephrines. J Clin Endocrinol Metab 1995; 80: 3009 - 3017.

64 Esler $\mathrm{M}$ et al. Contribution of individual organs to total noradrenaline release in humans. Acta Physiol Scand Suppl 1984; 527: $11-16$ 